OPEN ACCESS

Edited by:

Pierantonio Laveneziana,

INSERM U1158 Neurophysiologie

Respiratoire Expérimentale et

Clinique, France

Reviewed by:

Georgios Kaltsakas,

King's College London,

United Kingdom

Claudio Tantucci,

University of Brescia, Italy

*Correspondence:

Guilherme Augusto de Freitas

Fregonezi

fregonezi.guilherme@gmail.com

Specialty section: This article was submitted to

Respiratory Physiology,

a section of the journal

Frontiers in Physiology

Received: 02 February 2020

Accepted: 30 April 2020

Published: 09 June 2020

Citation:

Otto-Yáñez M,

Sarmento da Nóbrega AJ,

Torres-Castro R, Araújo PRS,

Carvalho de Farias CA

Dornelas De Andrade AF, Puppo H,

Resqueti VR and Fregonezi GAF (2020) Maximal Voluntary Ventilation

Should Not Be Estimated From

the Forced Expiratory Volume in the First Second in Healthy People and COPD Patients.

Front. Physiol. 11:537.

doi: 10.3389/fphys.2020.00537

\section{Maximal Voluntary Ventilation Should Not Be Estimated From the Forced Expiratory Volume in the First Second in Healthy People and COPD Patients}

Matías Otto-Yáñez 1,2,3,4, Antônio José Sarmento da Nóbrega ${ }^{3,4}$, Rodrigo Torres-Castro5, Palomma Russelly Saldanha Araújo ${ }^{3,4}$, Catharinne Angélica Carvalho de Farias ${ }^{3,4}$, Armele de Fátima Dornelas De Andrade ${ }^{6}$, Homero Puppo ${ }^{5}$, Vanessa Regiane Resqueti ${ }^{3,4}$ and Guilherme Augusto de Freitas Fregonezi3,4*

${ }^{1}$ Physical Therapy, Universidad Autónoma de Chile, Santiago, Chile, ${ }^{2}$ Programa de Doutorado em Biotecnologia RENORBIO, Universidade Federal do Rio Grande do Norte, Natal, Brazil, ${ }^{3}$ PneumoCardioVascular Lab/Hospital Universitário Onofre Lopes, Empresa Brazileira de Serviços Hospitalares (EBSERH), Universidade Federal do Rio Grande do Norte (UFRN), Natal, Brazil, ${ }^{4}$ Laboratório de Inovação Tecnológica em Reabilitação, Departamento de Fisioterapia, Universidade Federal do Rio Grande do Norte (UFRN), Natal, Brazil, ${ }^{5}$ Department of Physical Therapy, Faculty of Medicine, University of Chile, Santiago, Chile, ${ }^{6}$ Departamento de Fisioterapia, Universidade Federal do Pernambuco, Recife, Brazil

Purpose: To evaluate the concordance between the value of the actual maximum voluntary ventilation (MV) and the estimated value by multiplying the forced expiratory volume in the first second $\left(F E V_{1}\right)$ and a different value established in the literature.

Methods: A retrospective study was conducted with healthy subjects and patients with stable chronic obstructive pulmonary disease (COPD). Five prediction formulas MVV were used for the comparison with the MVV values. Agreement between MVV measured and MWV obtained from five prediction equations were studied. FEV 1 values were used to estimate MVV. Correlation and agreement analysis of the values was performed in two groups using the Pearson test and the Bland-Altman method; these groups were one group with 207 healthy subjects and the second group with 83 patients diagnosed with COPD, respectively.

Results: We recruited 207 healthy subjects (105 women, age $47 \pm 17$ years) and 83 COPD patients (age $66 \pm 6$ years; 29 GOLD II, 30 GOLD III, and 24 GOLD IV) for the study. All prediction equations presented a significant correlation with the MVV value (from 0.38 to $0.86, p<0.05$ ) except for the GOLD II subgroup, which had a poor agreement with measured MVV. In healthy subjects, the mean difference of the value of bias (and limits of agreement) varied between $-3.9 \%$ (-32.8 to $24.9 \%)$, and $27 \%$ (-1.4 to $55.3 \%)$. In COPD patients, the mean difference of value of bias (and limits of agreement) varied between $-4.4 \%$ (-49.4 to $40.6 \%$ ), and $26.3 \%$ (-18.3 to $70.9 \%)$. The results were similar in the subgroup analysis. 
Conclusion: The equations to estimate the value of MV present a good degree of correlation with the real value of MV, but they also show a poor concordance. For this reason, we should not use the estimated results as a replacement for the real value of MW.

Keywords: maximal voluntary ventilation, forced expiratory volume in the first second, prediction formulas, prediction equation, COPD

\section{INTRODUCTION}

The maximal voluntary ventilation (MVV) is the largest amount of air that a person can inhale and then exhale during a 12to 15-s interval with maximal voluntary effort (Neder et al., 1999). This maneuver was used to provide information about the functioning of the inspiratory pump and chest wall and is used to evaluate maximum ventilatory capacity (Colwell and Bhatia, 2017) and respiratory muscle endurance, but the last ERS statement on respiratory muscle tests does not recommend its use for these purposes because mechanical aspects of the chest wall and lung tissue can affect the MVV value (Laveneziana et al., 2019). It is used for indirect calculation of the ventilatory reserve through a relationship with minute volume during a maximum exercise test (ATS/ACCP, 2003). The performance of this test can be modified by factors such as strength and endurance of the respiratory muscles and/or airways as well as chest wall biomechanics (Barreiro and Perillo, 2004; Pellegrino et al., 2005; Suh and Lee, 2017). From a technical point of view, the mobilized volume is extrapolated to the volume of air that would be moved in $60 \mathrm{~s}$ in order to avoid prolonged hyperventilation (Neufeld et al., 2018), and the result is expressed in liters/minute with an accuracy of $\pm 10 \%( \pm 15 \mathrm{~L} / \mathrm{min}$; ATS/ACCP, 2003).

Evaluation through this maneuver, together with other evaluations of lung function, was used for the follow-up of neuromuscular diseases (Rochester and Esau, 1994), and the prediction of the risk of postoperative complications (Bevacqua, 2015). Another important use is in cardiopulmonary exercise testing because it provides useful information for determining the ventilatory reserve (Ferrazza et al., 2009; Arena and Sietsema, 2011). The assessment of MVV is also used as a target for respiratory muscle training with normocapnic hyperpnea modality (Markov et al., 2001). In the past years, several equations have been described in the literature to estimate the MVV value, and the majority of these studies use the multiplication of the forced expiratory volume in the first second $\left(\mathrm{FEV}_{1}\right)$ values by a constant (Cara, 1953; Gandevia and Hugh-Jones, 1957; Miller et al., 1959; Simonsson, 1963; Campbell, 1982). These predictive equations were developed to avoid the use of expensive equipment and patients' intense ventilatory effort (Carter et al., 1987; Stein et al., 2003). Recently, the new publication of the Statement on Respiratory Muscle Testing of the European Respiratory Society (ERS) recommends estimating the MVV value as the $\mathrm{FEV}_{1} \times 30$ or 40 (Laveneziana et al., 2019). It is possible that these formulas were developed in a different historical context, where the availability of spirometry equipment that also evaluated MVV was scarce.
Additionally, the majority of the prediction formulas were developed by linear regression analysis and were validated based on good correlation values. However, the correlation coefficient is a measure of strength of the relationship between two variables and does not allow the evaluation of agreement nor accuracy between instruments (Carter et al., 1987). Thus, there is a lack of evidence based on concordance analysis between the values obtained from MVV and the estimated values obtained through the formulas.

In this context, the objective of this study was to evaluate the agreement between the direct MVV measure values and those obtained through equations based on $\mathrm{FEV}_{1}$ values in healthy people and chronic obstructive pulmonary disease (COPD) patients. Given the complexity of the respiratory system and the various factors that interact in the MVV test, we hypothesized that both direct and estimated values did not have an acceptable agreement in healthy people and COPD patients.

\section{MATERIALS AND METHODS}

A retrospective study was conducted with healthy subjects and patients with COPD. Data obtained from two previously conducted studies were analyzed (Araújo et al., 2012; Farias et al., 2014). These studies are approved by the Research Ethics Committee of Universidade Federal do Rio Grande do Norte (UFRN), Natal, RN, Brazil, under protocols 260/08 and 449/2010 (Brazilian Clinical Trials Registry RBR-7bqxm2) and done according to the Declaration of Helsinki of 1975. The evaluations of the healthy population were carried out between April 2009 and March 2010. COPD patients were evaluated between May 2011 and April 2012. Self-reported healthy subjects recruited from the university community with ages between 20 and 80 years, non-athletes, and with no history of smoking or pulmonary or neurological diseases composed the healthy group. The healthy ones with spirometric values below predicted ( $<80 \%$ of forced vital capacity, FVC, and/or $\mathrm{FEV}_{1}$, and below the lower limit of normality) were excluded. The patients with COPD were recruited in the respiratory outpatient clinic of the Onofre Lopes University Hospital (Natal, Brazil). Inclusion criteria were clinically stable patients, following the GOLD guidelines, with a post-bronchodilator spirometry value of $\mathrm{FEV}_{1} / \mathrm{FVC}$ less than $70 \%, \mathrm{PaO}_{2}>55 \mathrm{mmHg}$ at rest with no recommendation for prescribing home oxygen therapy, and no other significant diseases that could prevent patient evaluation (Singh et al., 2019). Those with psychiatric disturbances, heart disease, or neurological or neuromuscular diseases associated were excluded. All patients gave informed consent. 


\section{Measurements}

Spirometry was used to perform the pulmonary function tests using a DATOSPIR-120 spirometer (SibelMed ${ }^{\circledR}$, Barcelona, Spain) according to the recommendations of the ATS/ERS guidelines (Miller et al., 2005). Three technically acceptable and reproducible forced expiratory curves were obtained for each participant. Variability between them was $<5 \%$, and only the curve with the best performance was considered for analysis. The predictive reference values for the Brazilian population were calculated according to de Castro Pereira et al. (2007), and the $\mathrm{FVC}, \mathrm{FEV}_{1}$, and $\mathrm{FEV}_{1} / \mathrm{FVC}$ in their absolute and relative values were considered for analysis. For the MVV, the participants were instructed to maximize ventilation by inhaling and exhaling as quickly and deeply as possible for 15 s (Miller et al., 2005), and values were expressed in liters per minute. The estimated MVV values based on the predictive formulas were determined by multiplying the $\mathrm{FEV}_{1}$, acquired during spirometry, by a constant (Table 1; Cara, 1953; Gandevia and Hugh-Jones, 1957; Miller et al., 1959; Simonsson, 1963; Campbell, 1982). Five equations were included. Two of the five included equations (Equations 2 and 3) are theoretical mathematical models, clinically not tested.

\section{Statistical Analysis}

Data were expressed as mean \pm SD, otherwise stated. Estimated MVV values were compared with the direct measure of MVV using Student's $t$ test for paired samples with a significance level of $p<0.05$. Pearson coefficients of correlation were also performed between direct and estimated MVV values. The following classification was used to interpret the values found: negligible correlation $(r<0.10)$, weak correlation $(r \geq 0.1$ to 0.39 ), moderate correlation ( $r \geq 0.40$ to 69$)$, strong correlation $(r \geq 0.70$ to 0.89$)$, and very strong correlation $(r=0.90$ to 1 ; Schober et al., 2018).

Agreements were evaluated using Bland-Altman plots (Bland and Altman, 1986), and the results were presented as bias (percentage of the difference between measured and estimated MVV values) and limits of agreement ( $\pm 1.96 \mathrm{SD})$. The 95\% confidence intervals for both the bias and the limits of agreement were also added (Giavarina, 2015). Acceptable limits to the value of the equations would be accepted given a mean bias $\leq 5 \%$, limits of agreement $\leq 10 \%$ (ATS/ACCP, 2003), and a $95 \%$ confidence interval of the mean bias within the line of equity of the Bland-Altman plot (i.e., 0\% difference; Giavarina, 2015). Subgroup analysis was also conducted for healthy individuals

TABLE 1 | Prediction equations.

\begin{tabular}{lll}
\hline Authors & & Prediction equation \\
\hline Simonsson, 1963 & Equation 1 & $\mathrm{FEV}_{1} \times 30$ \\
Gandevia and Hugh-Jones, 1957 & Equation 2 & $\mathrm{FEV}_{1} \times 35$ \\
Cara, 1953 & Equation 3 & $\mathrm{FEV}_{1} \times 37.5$ \\
Campbell, 1982 & Equation 4 & $\mathrm{FEV}_{1} \times 40$ \\
Miller et al., 1959 & Equation 5 & $\mathrm{FEV}_{1} \times 41$ \\
\hline
\end{tabular}

Abbreviations: $F E V_{1}$, forced expiratory volume in the first second in liters. (male and female) and for COPD patients (GOLD II, GOLD III, and GOLD IV).

Data were analyzed using GraphPad Prism 6 (GraphPad Software Inc., San Diego, CA, United States) software, and the level of significance was set at $p<0.05$ with a twotailed approach.

\section{RESULTS}

\section{Healthy Subjects}

Data on 207 healthy people ( $47 \pm 17$ years, 102 male, and 105 female) were included. Anthropometric characteristics, spirometry, and data from MVV are shown in Table 2. For Student's $t$ test, only Equation 4 showed no significant differences with the direct measured MVV value. Regarding subgroup analysis, measured MVV values were not statistically different from Equations 4 and 5 in males. All equations were statistically different in females (Table 3).

The results of all equations were significantly correlated with the measured MVV values (all $r s=0.86, p s<0.0001$ ). Similar results were also found for both male $(r=0.75, p<0.0001)$ and female $(r=0.82, p<0.0001)$ subgroups. As shown in Table 4, the mean bias of all equations varied from $-3.9 \%$ (Equation 5 ) to 27\% (Equation 1), and only Equations 3-5 presented a mean bias $\leq 5 \%$. For males, this variation was between $-1.7 \%$ and $29.1 \%$ and, for females, between -6.2 and $24.7 \%$ (Figure 1).

\section{COPD Patients}

Data of 83 COPD patients $(65.5 \pm 6.4$ years, 29 GOLD II, 30 GOLD III, and 24 GOLD IV) were included. Equations 3-5 showed no significant differences from measured MVV values (Table 3). All equations were also significantly correlated with measured MVV values (all $r \mathrm{~s}=0.76, p s<0.0001$ ). When analyzing subgroups, significant correlations were found only for GOLD III $(r=0.38, p=0.04)$, and GOLD IV $(r=0.49, p=0.02)$.

Poor agreements were also found between measured MVV values and those predicted from equations. For all patients, the mean bias varied from $-4.4 \%$ (Equation 5) to $26.3 \%$ (Equation 1; Table 4). Despite Equations 3-5 presenting a mean bias of $\leq 5 \%$, the limits of agreement were always greater than $40 \%$ (Figure 2).

\section{DISCUSSION}

Several studies use the estimation of MVV value from a prediction equation with the $\mathrm{FEV}_{1}$ value, usually multiplying the $\mathrm{FEV}_{1}$ by 35 or 40 (Callens et al., 2009; Werkman et al., 2011; Stevens et al., 2013). The main finding of this study was that, apart from strong correlations, a poor concordance was observed between measured MVV values and those estimated from equations. Although most of the formulas have statistically significant correlations, it is not possible to establish that both evaluation methods are equivalent through these statistical tests. When analyzing Bland-Altman plots, a poor agreement was observed. In the case of healthy subjects, the mean bias of all equations varied from $-3.9 \%$ (Equation 5) to $27 \%$ (Equation 1), 
TABLE 2 | Anthropometric and spirometric values of healthy and COPD subjects.

\begin{tabular}{|c|c|c|c|c|c|c|c|}
\hline & \multicolumn{3}{|c|}{ Healthy } & \multicolumn{4}{|c|}{ COPD } \\
\hline & All & Male & Female & All & GOLD II & GOLD III & GOLD IV \\
\hline Subjects(n) & 207 & 102 & 105 & 83 & 29 & 30 & 24 \\
\hline $\mathrm{Age}_{(\text {years })}$ & $47 \pm 16.9$ & $46.3 \pm 16.4$ & $47.7 \pm 17.3$ & $65.5 \pm 6.4$ & $65.4 \pm 6.2$ & $65.4 \pm 6.6$ & $65.6 \pm 6.7$ \\
\hline Weight $_{(k g)}$ & $70.1 \pm 12.3$ & $77.3 \pm 10.8$ & $63.0 \pm 9.1$ & $71.5 \pm 11.7$ & $75.6 \pm 13.0$ & $69.8 \pm 11.0$ & $68.6 \pm 10.0$ \\
\hline Height $_{(m)}$ & $1.66 \pm 0.93$ & $1.72 \pm 0.80$ & $1.60 \pm 0.67$ & $1.65 \pm 0.69$ & $1.64 \pm 0.85$ & $1.65 \pm 0.67$ & $1.66 \pm 4.6$ \\
\hline $\mathrm{BMI}_{(\mathrm{kg} / \mathrm{m} 2)}$ & $25.3 \pm 3.6$ & $26.0 \pm 3.7$ & $24.5 \pm 3.4$ & $26.2 \pm 3.9$ & $28 \pm 4.2$ & $25.2 \pm 3.3$ & $24.9 \pm 3.4$ \\
\hline $\mathrm{FVC}_{(\mathrm{L})}$ & $3.8 \pm 1.0$ & $4.4 \pm 0.8$ & $3.1 \pm 0.6$ & $2.6 \pm 0.7$ & $2.8 \pm 0.7$ & $2.5 \pm 0.6$ & $2.3 \pm 0.6$ \\
\hline $\mathrm{FVC}_{(\% \text { pred })}$ & $95.3 \pm 10.7$ & $94.3 \pm 10.1$ & $96.0 \pm 11.3$ & $64.6 \pm 15.1$ & $75.9 \pm 12.4$ & $61.3 \pm 12.7$ & $55.1 \pm 12.6$ \\
\hline $\mathrm{FEV}_{1(L)}$ & $3.2 \pm 0.8$ & $3.7 \pm 0.7$ & $2.7 \pm 0.6$ & $1.2 \pm 0.4$ & $1.6 \pm 0.3$ & $1.1 \pm 0.2$ & $0.7 \pm 0.1$ \\
\hline $\mathrm{FEVI}_{(\% \text { pred })}$ & $99.4 \pm 11.3$ & $97.9 \pm 11.4$ & $100.9 \pm 10.9$ & $41.1 \pm 17.9$ & $60.9 \pm 12.5$ & $37.1 \pm 6.6$ & $22.3 \pm 3.9$ \\
\hline $\mathrm{FEV}_{1} / \mathrm{FVC}_{(\mathrm{L})}$ & $0.85 \pm 0.06$ & $0.84 \pm 0.06$ & $0.86 \pm 0.06$ & $0.46 \pm 0.14$ & $0.59 \pm 0.09$ & $0.46 \pm 0.10$ & $0.30 \pm 0.06$ \\
\hline $\mathrm{MVV}_{(\mathrm{L} / \mathrm{min})}$ & $126.4 \pm 36.6$ & $149.4 \pm 33.3$ & $104.3 \pm 23.6$ & $46.5 \pm 18.2$ & $63.9 \pm 13.6$ & $45.0 \pm 10.7$ & $27.3 \pm 6.7$ \\
\hline $\mathrm{MIP}_{(\mathrm{cmH} 20)}$ & $101.5 \pm 26.4$ & $114.0 \pm 28.1$ & $89.4 \pm 17.7$ & $70.7 \pm 18.9$ & $72.5 \pm 22.4$ & $71.4 \pm 18.6$ & $67.8 \pm 15$ \\
\hline $\operatorname{MEP}_{(\mathrm{cmH} 20)}$ & $134.3 \pm 42.5$ & $160.2 \pm 42.5$ & $109.3 \pm 23.5$ & $134.6 \pm 43.2$ & $120.6 \pm 46.6$ & $140.6 \pm 47.5$ & $143.9 \pm 27.9$ \\
\hline
\end{tabular}

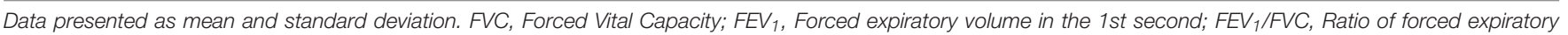

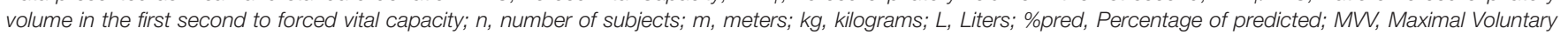
Ventilation; MIP, Maximal Inspiratory Pressure; and MEP, Maximal Expiratory Pressure.

TABLE 3 | Mean MW values measured directly and predicted MW values.

\begin{tabular}{|c|c|c|c|c|c|c|c|}
\hline & \multicolumn{3}{|c|}{ Healthy } & \multicolumn{4}{|c|}{ COPD } \\
\hline & All & Male & Female & All & GOLD II & GOLD III & GOLD IV \\
\hline Subjects $_{(n)}$ & 207 & 102 & 105 & 83 & 29 & 30 & 24 \\
\hline $\mathrm{MWV}_{(\mathrm{L} / \mathrm{min})}$ & $126.4 \pm 36.6$ & $149.4 \pm 33.3$ & $104.3 \pm 23.6$ & $46.5 \pm 18.2$ & $63.9 \pm 13.6$ & $45.0 \pm 10.7$ & $27.3 \pm 6.7$ \\
\hline Equation $1_{(\mathrm{L} / \mathrm{min})}$ & $95.2 \pm 23.9^{\star \star}$ & $110.0 \pm 20.2^{\star \star}$ & $81.1 \pm 17.9^{\star \star}$ & $35.2 \pm 13.0^{\star \star}$ & $49.1 \pm 8.4^{\star \star}$ & $33.5 \pm 5.6^{\star \star}$ & $20.8 \pm 4.2^{\star \star}$ \\
\hline Equation $2_{(\mathrm{L} / \mathrm{min})}$ & $111.1 \pm 27.9^{\star \star}$ & $128.3 \pm 23.6^{\star \star}$ & $94.6 \pm 20.8^{\star \star}$ & $41.1 \pm 15.2^{\star \star}$ & $57.2 \pm 9.8^{\star}$ & $39.1 \pm 6.5^{\star}$ & $24.2 \pm 4.9^{\star}$ \\
\hline Equation $3_{(\llcorner/ \mathrm{min})}$ & $119.1 \pm 29.9^{\star \star}$ & $137.4 \pm 25.3^{\star \star}$ & $101.4 \pm 22.3^{\star}$ & $44.1 \pm 16.3$ & $61.3 \pm 10.5$ & $41.9 \pm 6.9$ & $26.0 \pm 5.2$ \\
\hline Equation $4_{(\llcorner/ \mathrm{min})}$ & $127.0 \pm 31.8$ & $146.6 \pm 27.0$ & $108.2 \pm 23.8^{\star}$ & $47.0 \pm 17.4$ & $65.4 \pm 11.2$ & $44.6 \pm 7.4$ & $27.7 \pm 5.6$ \\
\hline Equation $5_{(\mathrm{L} / \mathrm{min})}$ & $130.1 \pm 32.7^{\star}$ & $150.3 \pm 27.6$ & $110.9 \pm 24.4^{\star \star}$ & $48.2 \pm 17.8$ & $67.0 \pm 11.5$ & $45.8 \pm 7.6$ & $28.4 \pm 5.7$ \\
\hline
\end{tabular}

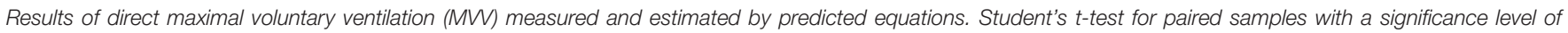

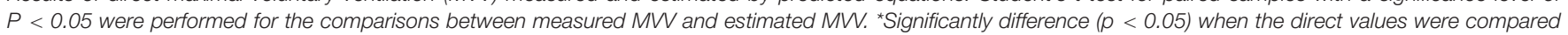

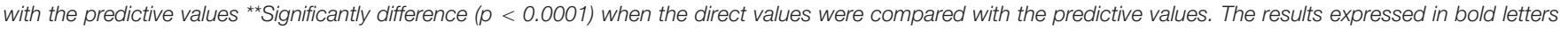
correspond to the equations that did not show significant differences with the direct value of MWV. Data are presented are liter per minute (L/min).

and only Equations 3-5 presented a mean bias $\leq 5 \%$. For males, this variation was between -1.7 and $29.1 \%$ and, for females, between -6.2 and $24.7 \%$. Nevertheless, as observed in Figure 1, the prediction equations not only overestimated (Equation 3) or underestimated (Equations 4 and 5) the measured MVV values, but also the limits of agreement were greater than that $10 \%$ recommended by scientific societies (Miller et al., 2005). All the equations presented a poor agreement. The limit of agreement analysis revealed a wide variation among equations. Although mean differences (bias) of Equations 2 and 3 in healthy individuals may be within the limits of acceptability of the test, its limits of agreement present a large dispersion, which does not allow validating the estimated value of MVV as a real value. These equations are based on a linear mathematical model, but possibly, the behavior of the respiratory system does not respond to a linear model. Therefore, it is complex to predict real physiological values using prediction formulas based on linear mathematical models.
We have found a wide average discrepancy between methods. This important discrepancy between the real and the estimated value could generate an underestimation or overestimation when an assessment test or isocapnic training about a percentage of the MVV value is established. Also, some formulas have differences close to $30 \%$ compared to the real value, which could generate important errors in the clinical interpretation if we only estimate the MVV value. The limits of the agreement and the bias value are quite wide, so it is not possible to establish that both methods are equivalent. There is no clear trend regarding the behavior of differences with the different equations. The dispersion of the points was always greater than the acceptable validity limits for this test.

On the other hand, these equations include parameters as $\mathrm{FEV}_{1}$ in healthy subjects, but the patients with chronic respiratory diseases may have abnormalities in the pulmonary function test that may change the accuracy of the measured MVV. Additionally, we analyze the equations in COPD patients 


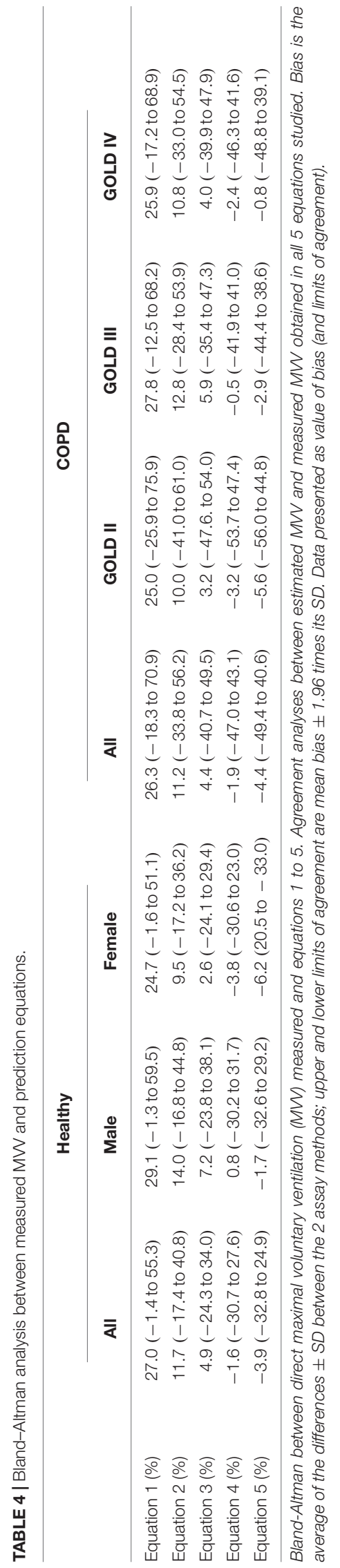

to explore if the agreement presents the same behavior in both normal and pathological conditions.

The behavior was the same; poor agreements were also found between the measured MVV values and the ones predicted from equations. The mean bias varied from $-4.4 \%$ (Equation 5) to $26.3 \%$ (Equation 1) with the greater variation observed in the GOLD III subgroup (from -2.9.0\% with Equation 5 to $27.8 \%$ with Equation 1). Despite Equations 3-5 presenting a mean bias of $\leq 5 \%$, the limits of agreement were always greater than $40 \%$.

Maximal voluntary ventilation has poor specificity, is highly effort dependent, and can be uncomfortable for the patients. MVV depends on motivation and can be tiring for some patients (Laveneziana et al., 2019). It is reported that MVV depends on inspiratory and expiratory breathing effort in all type of subjects. The inspiratory airflow depends mainly on inspiratory muscle power in overcoming static elastic recoil of the respiratory system and resistive forces of the lung, and the expiratory airflow relies mainly on lung recoil (Lavietes et al., 1979; Milic-Emili and Orzalesi, 1998). Respiratory work is affected by respiratory rate, presenting a decrease in tidal volume and breathing power as the respiratory rate increases, and expiratory muscles have less time to harness the potential chemical energy for their action. This could affect the validity of the MVV estimation by means of equations because the expiratory technique during spirometry differs greatly from how it is performed in the MVV (MilicEmili and Orzalesi, 1998). In normal subjects, lung recoil is known to be the major determinant of expiratory airflow in MVV performance. The use of equations of prediction based on $\mathrm{FEV}_{1}$ fails to take into account some physical characteristics that influence MVV (Neufeld et al., 2018), such as height, sex, and age. The literature has shown that individuals who smoke or are pregnant and people with cystic fibrosis had MVV values that deviate from sex, height, and age-matched controls (Stein et al., 2003; Hasan et al., 2013; Tell et al., 2014; Neufeld et al., 2018). The MVV execution involves repeated, rapid, and maximum ventilation, generating an increase in inspiratory and expiratory volumes in comparison with the tidal volume. COPD patients frequently present a phenomenon of hyperinflation, which generates a progressive decrease in inspiratory capacity (Gagnon et al., 2014). MVV is an assessment test that could be affected by hyperinflation, and this is the principal reason why we argue that it's impossible to estimate the MVV value through a single expiratory parameter as the $\mathrm{FEV}_{1}$. This can be confirmed by the evidence of increases in the MVV value after lung volume reduction surgery in COPD patients (Benditt et al., 1997; Martinez et al., 1997).

Our results are in line with Nunes et al. (2016), who carried out a concordance study between the measured and estimated MVV value in 119 patients with pulmonary hypertension. The result showed that there was an overestimation of estimated values of lower measured MVV and underestimation at higher values. These findings confirm that it is not possible to predict the MVV value only through a multiple of the $\mathrm{FEV}_{1}$ value. This study only analyzes healthy subjects and COPD patients, so it is relevant to evaluate the concordance of these formulas 

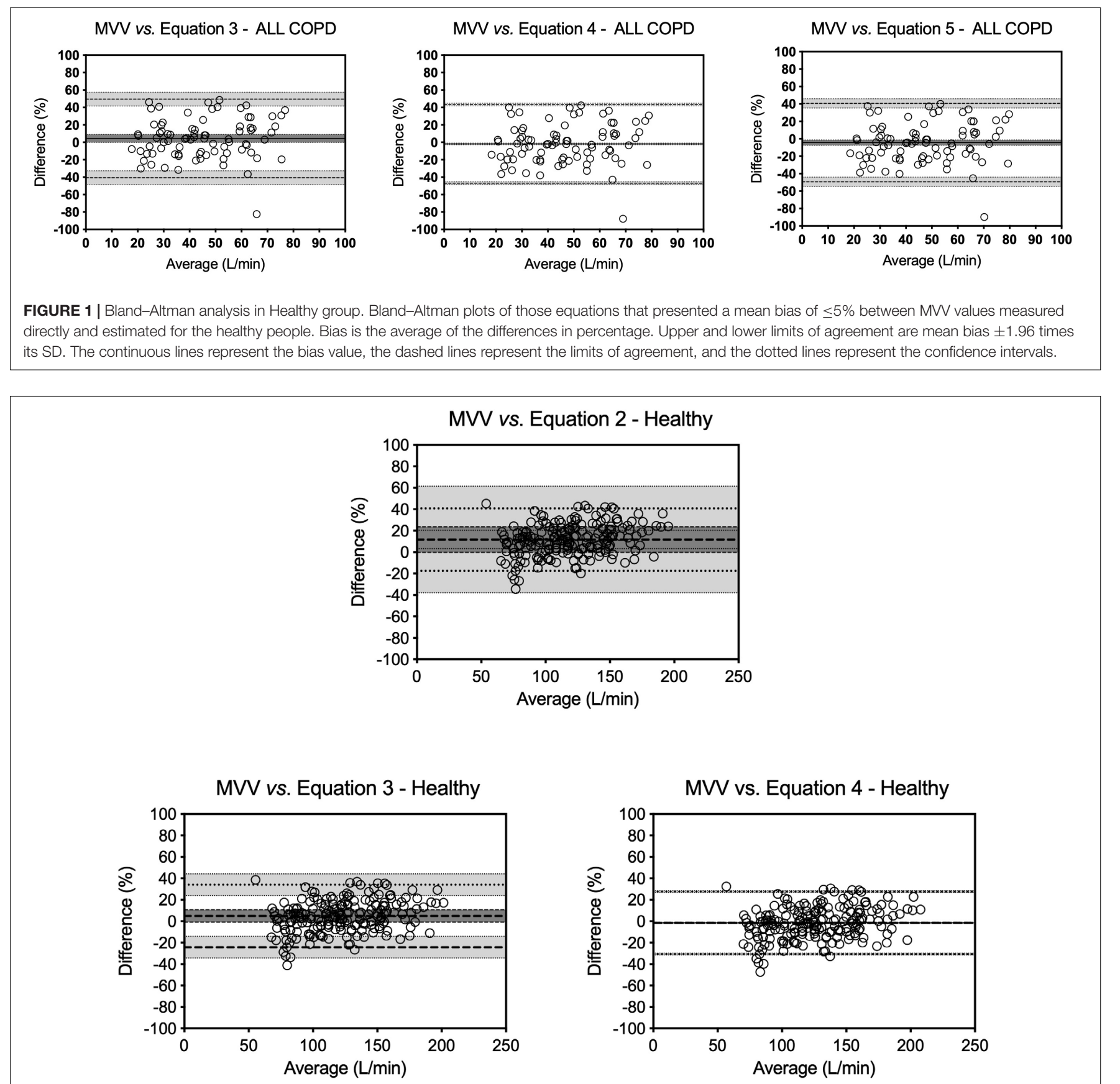

FIGURE 2 | Bland-Altman analysis in COPD group. Bland-Altman plots of those equations that presented a mean bias of $\leq 5$ between MW values measured directly and estimated for the COPD patients. Bias is the average of the differences in percentage. Upper and lower limits of agreement are mean bias \pm 1.96 times its SD. The continuous lines represent the bias value, the dashed lines represent the limits of agreement, and the dotted lines represent the confidence intervals.

in pathologies that present a restrictive ventilatory alteration. Our results confirm that, in order to know the value of the MVV, it is necessary to evaluate it not using a formula with the $\mathrm{FEV}_{1}$ value. The time when the spirometry teams did not evaluate the MVV is behind, and practically, most of the spirometry equipment allows this ventilatory test. The measurement of the MVV is considered an easily realizable test, and it is currently possible to perform it with most of the equipment available in the market, so it would not be advisable to replace its value by an estimate from the value of $\mathrm{FEV}_{1}$.

The MVV assessment provided complementary information and has clinical implications not only in healthy subjects and obstructive patients, but also in patients with restrictive diseases, as in the case of neuromuscular disease, given that they also perform MVV in the midrange of vital capacity. In this 
sense, MVV reflects the efficiency of lung recoil. The breathing pattern has a wide range of irregularities during the entire breathing period, and the calculation can conduct a mistake (Suh et al., 2019).

On the other hand, there are assessments that use the MVV, for example, the analysis of cardiopulmonary exercise testing, a routine evaluation of physical capacity. This outcome is useful for measuring the ventilatory reserve in patients with respiratory and cardiovascular disease (Guazzi et al., 2017). Taking this into account, the healthcare professional can distinguish between a cardiovascular and respiratory profile in the case of exercise intolerance (Nathan et al., 2019). However, we need to know the ventilatory reserve for this analysis, and the calculation of MVV provides an error risk.

In spite of having good levels of correlation and that some do not present significant differences with the real value of the MVV, when evaluating the agreement of these values, it is shown that it is not possible to consider these MVV evaluation formulas as valid due to presenting limits of agreement with a substantial dispersion.

Our study has some limitations. The number of patients diagnosed with COPD classified by GOLD categories is small. This only allows a global analysis of COPD patients that does not consider the severity of the disease. On the other hand, we did not analyze the hyperinflation. This parameter provides essential information because the efficiency of the movement of the diaphragm muscle depends on its correct biomechanical position, and the hyperinflation can influence the measure of MVV.

\section{CONCLUSION}

In conclusion, MVV values estimated from equations are scattered and may underestimate or overestimate the real MVV value in healthy people and COPD patients. For this reason, a direct MVV measurement is suggested in this population instead of estimations through prediction equations. In consequence, we should not use

\section{REFERENCES}

Araújo, P. R. S., Resqueti, V. R., Nascimento, J. Jr., Carvalho, L. D. A., Cavalcanti, A. G. L., Silva, V. C., et al. (2012). Reference values for sniff nasal inspiratory pressure in healthy subjects in brazil: a multicenter study. J. Bras. Pneumo. 38, 700-707. doi: 10.1590/S1806-37132012000600004

Arena, R., and Sietsema, K. E. (2011). Cardiopulmonary exercise testing in the clinical evaluation of patients with heart and lung disease. Circulation 123, 668-680. doi: 10.1161/CIRCULATIONAHA.109.914788

ATS/ACCP (2003). ATS/ACCP statement on cardiopulmonary exercise testing. Am. J. Respir. Crit. Care. Med. 167, 211-277. doi: 10.1164/rccm.167.2.211

Barreiro, T. J., and Perillo, I. (2004). An approach to interpreting spirometry. Am. Fam. Phys. 69, 1107-1116.

Benditt, J. O., Lewis, S., Wood, D. E., Klima, L., and Albert, R. K. (1997). Lung volume reduction surgery improves maximal o2 consumption, maximal minute ventilation, $\mathrm{o} 2$ pulse, and dead space-to-tidal volume ratio during leg cycle ergometry. Am. J. Respir. Crit. Care. Med. 156, 561-566. doi: 10.1164/ajrccm. 156.2.9611032 the estimated results as a replacement for the real value of MVV.

\section{DATA AVAILABILITY STATEMENT}

The datasets generated for this study are available on request to the corresponding author.

\section{ETHICS STATEMENT}

The studies involving human participants were reviewed and approved by Research Ethics Committee of Universidade Federal do Rio Grande do Norte (UFRN), Natal, RN, Brazil, under protocol 260/08 and 449/2010. The patients/participants provided their written informed consent to participate in this study.

\section{AUTHOR CONTRIBUTIONS}

GF, VR, CC, and AD contributed to design the study. PA, CC, and GF conducted assessments. MO-Y, AS, and GF analyzed, interpreted all experimental data, and were major contributors in writing the manuscript. All authors revised the manuscript.

\section{FUNDING}

GF received a grant from CNPq number 312876/2018-1, and VR received a grant from $\mathrm{CNPq}$ number $315580 / 2018-6$. This study was financed in part by the Coordinação de Aperfeiçoamento de Pessoal de Nível Superior - Brazil (CAPES) - Finance Code 001.

\section{ACKNOWLEDGMENTS}

The researchers would like to thank the to all the people who voluntarily participated in this investigation.

Bevacqua, B. K. (2015). Pre-operative pulmonary evaluation in the patient with suspected respiratory disease. Indian J. Anaesth. 59, 542-549. doi: 10.4103/ 0019-5049.165854

Bland, J. M., and Altman, D. (1986). Statistical methods for assessing agreement between two methods of clinical measurement. Lancet 327, 307-310. doi: 10.1016/s0140-6736(86)90837-8

Callens, E., Graba, S., Gillet-Juvin, K., Essalhi, M., Bidaud-Chevalier, B., Peiffer, C., et al. (2009). Measurement of dynamic hyperinflation after a 6-minute walk test in patients with COPD. Chest. 136, 1466-1472. doi: 10.1378/chest.090410

Campbell, S. C. (1982). A comparison of the maximum voluntary ventilation with the forced expiratory volume in one second: an assessment of subject cooperation. J. Occup. Med. 24, 531-533.

Cara, M. (1953). Bases physiques pour un essai de mécanique ventilatoire avec application a la cinésitherapie. Poumon 9, 371-428.

Carter, R., Peavler, M., Zinkgraf, S., Williams, J., and Fields, S. (1987). Predicting maximal exercise ventilation in patients with chronic obstructive pulmonary disease. Chest 92, 253-259. doi: 10.1378/chest.92.2.253 
Colwell, K. L., and Bhatia, R. (2017). Calculated versus measured MVV-surrogate marker of ventilatory CPET. Med. Sci. Sports Exerc. 49, 1987-1992. doi: 10. 1249/MSS.0000000000001318

de Castro Pereira, C. A., Sato, T., and Rodrigues, S. C. (2007). Novos valores de referência para espirometria forçada em brasileiros adultos de raça branca. J. Bras. Pneumol. 33, 397-406. doi: 10.1590/S1806-37132007000400008

Farias, C. C., Resqueti, V., Dias, F. A., Borghi-Silva, A., Arena, R., and Fregonezi, G. A. (2014). Costs and benefits of pulmonary rehabilitation in chronic obstructive pulmonary disease: a randomized controlled trial. Braz. J. Phys. Ther. 18, 165-173. doi: 10.1590/s1413-355520120050 00151

Ferrazza, A., Martolini, D., Valli, G., and Palange, P. (2009). Cardiopulmonary exercise testing in the functional and prognostic evaluation of patients with pulmonary diseases. Respiration 77, 3-17. doi: 10.1159/000186694

Gagnon, P., Guenette, J. A., Langer, D., Laviolette, L., Mainguy, V., Maltais, F., et al. (2014). Pathogenesis of hyperinflation in chronic obstructive pulmonary disease. Int. J. Chron. Obstruct. Pulmon. Dis. 9, 187-201. doi: 10.2147/COPD. S38934

Gandevia, B., and Hugh-Jones, P. (1957). Terminology for measurements of ventilatory capacity: a report to the thoracic society. Thorax 12, 290-293. doi: 10.1136/thx.12.4.290

Giavarina, D. (2015). Understanding bland altman analysis. Biochem. Med. 25, 141-151. doi: 10.11613/BM.2015.015

Guazzi, M., Bandera, F., Ozemek, C., Systrom, D., and Arena, R. (2017). Cardiopulmonary exercise testing: what is its value? J. Am. Coll. Cardiol. 70, 1618-1636. doi: 10.1016/j.jacc.2017.08.012

Hasan, S. H. S., Rakkah, N. I., and Attaur-Rasool, S. (2013). Effect of smoking on respiratory pressures and lung volumes in young adults. Biomedica 29, 96-100.

Laveneziana, P., Albuquerque, A., Aliverti, A., Babb, T., Barreiro, E., Dres, M., et al. (2019). ERS Statement on respiratory muscle testing at rest and during exercise. Eur. Respir. J. 53:1801214. doi: 10.1183/13993003.01214-2018

Lavietes, M. H., Clifford, E., Silverstein, D., Stier, F., and Reichman, L. B. (1979). Relationship of static respiratory muscle pressure and maximum voluntary ventilation in normal subjects. Respiration 38, 121-126. doi: 10.1159/ 000194068

Markov, G., Spengler, C. M., Knoèpfli-Lenzin, C., Stuessi, C., and Boutellier, U. (2001). Respiratory muscle training increases cycling endurance without affecting cardiovascular responses to exercise. Eur. J. Appl. Physiol. 85, 233-239. doi: $10.1007 /$ s004210100450

Martinez, F. J., de Oca, M. M., Whyte, R. I., Stetz, J., Gay, S. E., and Celli, B. R. (1997). Lung-volume reduction improves dyspnea, dynamic hyperinflation, and respiratory muscle function. Am. J. Respir. Crit. Care. Med. 155, 1984-1990. doi: 10.1164/ajrccm.155.6.9196106

Milic-Emili, J., and Orzalesi, M. M. (1998). Mechanical work of breathing during maximal voluntary ventilation. J. Appl. Physiol. 85, 254-258. doi: 10.1152/jappl. 1998.85.1.254

Miller, M. R., Hankinson, J., Brusasco, V., Burgos, F., Casaburi, R., Coates, A., et al. (2005). Standardisation of spirometry. Eur. Respir. J. 26, 319-338. doi: 10.1183/09031936.05.00034805

Miller, W. F., Johnson, J. R., Robert, L., and Wu, N. (1959). Relationships between maximal breathing capacity and timed expiratory capacities. J. Appl. Physiol. 14, 510-516. doi: 10.1152/jappl.1959.14.4.510

Nathan, S. D., Barbera, J. A., Gaine, S. P., Harari, S., Martinez, F. J., Olschewski, H., et al. (2019). Pulmonary hypertension in chronic lung disease and hypoxia. Eur. Respir. J. 53, 1801914. doi: 10.1183/13993003.01914-2018

Neder, J. A., Andreoni, S., Lerario, M. C., and Nery, L. E. (1999). Reference values for lung function tests: ii. Maximal respiratory pressures and voluntary ventilation. Braz. J. Med. Biol. Res. 32, 719-727. doi: 10.1590/s0100879x1999000600007
Neufeld, E. V., Dolezal, B. A., Speier, W., and Cooper, C. B. (2018). Effect of altering breathing frequency on maximum voluntary ventilation in healthy adults. BMC. Pulm. Med. 18:89. doi: 10.1186/s12890-018-0650-4

Nunes, S. D. R. D. C., Figliolino, G. A., Ramos, R. P., Ferreira, E. V., Cepeda, A., Ivanaga, I., et al. (2016). Comparative analysis of estimated and measured maximal voluntary ventilation in patients with pulmonary hypertension. Eur. Respir. J. 48:A2260. doi: 10.1183/13993003.congress-2016.PA2260

Pellegrino, R., Viegi, G., Brusasco, V., Crapo, R., Burgos, F., Casaburi, R., et al. (2005). Interpretative strategies for lung function tests. Eur. Respir. J. 26, 948-968. doi: 10.1183/09031936.05.00035205

Rochester, D. F., and Esau, S. A. (1994). Assessment of ventilatory function in patients with neuromuscular disease. Clin. Chest Med. 15, 751-763.

Schober, P., Boer, C., and Schwarte, L. A. (2018). Correlation coefficients: appropriate use and interpretation. Anesth. Analg. 126, 1763-1768. doi: 10.1213/ANE.0000000000002864

Simonsson, B. G. (1963). IV. ventilatory capacities obtained from forced expirograms and from maximal $\mathrm{V}$ oluntary ventilation of various frequencies 1. Allergy 1963, 365-374. doi: 10.1111/j.1398-9995.1963.tb03195.x

Singh, D., Agusti, A., Anzueto, A., Barnes, P. J., Bourbeau, J., Celli, B. R., et al. (2019). Global strategy for the diagnosis, management, and prevention of chronic obstructive lung disease: the gold science committee report 2019. Eur. Respir. J. 53: 1900164. doi: 10.1183/13993003.00164-2019

Stein, R., Selvadurai, H., Coates, A., Wilkes, D. L., Schneiderman-Walker, J., and Corey, M. (2003). Determination of maximal voluntary ventilation in children with cystic fibrosis. Pediatr. Pulmonol. 35, 467-471. doi: 10.1002/ppul. 10298

Stevens, D., Stephenson, A., Faughnan, M., Leek, E., and Tullis, E. (2013). Prognostic relevance of dynamic hyperinflation during cardiopulmonary exercise testing in adult patients with cystic fibrosis. J. Cyst. Fibros. 12, 655-661. doi: 10.1016/j.jcf.2013.04.010

Suh, M. R., Kim, D. H., Jung, J., Kim, B., Lee, J. W., Choi, W. A., et al. (2019). Clinical implication of maximal voluntary ventilation in myotonic muscular dystrophy. Medicine 98:e15321. doi: 10.1097/MD.00000000000 15321

Suh, Y., and Lee, C. (2017). Genome-wide association study for genetic variants related with maximal voluntary ventilation reveals two novel genomic signals associated with lung function. Medicine96:e8530. doi: 10.1097/MD. 0000000000008530

Tell, A., Bagali, S., Aithala, M., Khodnapur, J., and Dhanakshirur, G. (2014). Alterations in minute ventilation, maximum voluntary ventilation and dyspneic index in different trimesters of pregnancy. Indian J. Physiol. Pharmacol. 58, 96-99.

Werkman, M., Hulzebos, H., Arets, H., Van der Net, J., Helders, P., and Takken, T. (2011). Is static hyperinflation a limiting factor during exercise in adolescents with cystic fibrosis? Pediatr. Pulmonol. 46, 119-124. doi: 10.1002/ppul. 21329

Conflict of Interest: The authors declare that the research was conducted in the absence of any commercial or financial relationships that could be construed as a potential conflict of interest.

Copyright (c) 2020 Otto-Yáñez, Sarmento da Nóbrega, Torres-Castro, Araújo, Carvalho de Farias, Dornelas De Andrade, Puppo, Resqueti and Fregonezi. This is an open-access article distributed under the terms of the Creative Commons Attribution License (CC BY). The use, distribution or reproduction in other forums is permitted, provided the original author(s) and the copyright owner(s) are credited and that the original publication in this journal is cited, in accordance with accepted academic practice. No use, distribution or reproduction is permitted which does not comply with these terms. 